\title{
AS FOTOGRAFIAS DO ARQUIVO DO GRUPO ESCOLAR DR. JOAQUIM ASSUMPÇÃO: IMAGENS DE PRÁTICAS ESCOLARES NO GRUPO ESCOLAR MODELO DO GOVERNO DE AUGUSTO SIMÕES LOPES (1924-1928), PELOTAS, RIO GRANDE DO SUL
}

\author{
Maria Augusta Martiarena de Oliveira \\ Universidade Federal de Pelotas - UFPel \\ martiarena.augusta@gmail.com \\ Elomar Tambara \\ Universidade Federal de Pelotas - UFPel \\ tambara@ufpel.edu.br \\ Giana Lange do Amaral \\ Universidade Federal de Pelotas - UFPel \\ giana@ufpel.edu.br
}

\section{RESUMO:}

Este artigo objetiva realizar a análise de fotografias do Grupo Escolar Dr. Joaquim Assumpção. Essa escola foi fundada durante o governo de Augusto Simões Lopes, que foi intendente da cidade de Pelotas, pelo Partido Republicano Rio-Grandense, de 1924 a 1928. Esse grupo escolar municipal foi construído para ser uma escola modelo para a cidade e concorrer com os dois Colégios Elementares Estaduais do mesmo nível, o Cassiano do Nascimento e o Félix da Cunha, existentes em Pelotas. Durante a pesquisa sobre o governo Simões Lopes, foi encontrado, na própria escola, um conjunto de fotografias originais datadas da época de sua inauguração e de seus primeiros meses de funcionamento. Tais imagens representam algumas práticas escolares existentes na década de 1920, além de enfatizar características da organização espacial e temporal das escolas, bem como da arquitetura escolar. Essas imagens permitem a compreensão do motivo pelo qual o referido grupo escolar encontrava-se no patamar mais elevado preconizado pelo "Regulamento da Instrucção", do governo Simões Lopes. Embora não sejam fotografias oficiais, tais imagens estão impregnadas do ideário governista republicano da época, especificamente, do referido governo.

Palavras-chave: Primeira República, fotografia, grupo escolar

The Photograph of the Dr. Joaquim Assumpção School Group archive: school practices images from the standard school group of the Augusto Simões Lopes' government (1924-1928), Pelotas, Rio Grande do Sul

\begin{abstract}
:
This article has as objective to realize de analysis of the School Group Dr. Joaquim Assumpção photographs. That school was founded during the Augusto Simões Lopes' government, mayor of the Pelotas City, by the Republican Party of Rio Grande do Sul , between 1924 and 1928. This municipal school group has been built for being a standard school for the city and to compete with the two schools of the state of the same level, Cassiano do Nascimento and Félix da Cunha, existing at the city. During the research about the Simões Lopes' government, it was encountered, in the referred school, a set of original photographs, dated of the time of its inauguration and its first month of activities. This images represent the school practices existing at the decade of 1920, aside from show
\end{abstract}


the space and temporal organization characteristics of the schools, as well as school architecture. This images permit the comprehension of the motif for this school group was found in the higher level established by the "Regulamento da Instrucção" (Instruction Rules), from the Simões Lopes' government. Although, they are not official pictures, this images are impregnated from the republican government ideas of this time, especially, from the referred government.

Key-words: First Republic, photograph, school group

\section{Introdução}

Augusto Simões Lopes foi intendente municipal de Pelotas, entre os anos de 1924 e 1928, pelo Partido Republicano Rio-Grandense. Durante seu governo, a fotografia teve muito destaque. Um conjunto bastante amplo de imagens de prédios escolares e do cotidiano escolar foi produzido e divulgado na imprensa. Nesse período foi inaugurado um grupo escolar considerado modelo, o qual ocupou papel central nas propagandas governamentais, o Grupo Escolar Dr. Joaquim Assumpção.

Nessa escola, que funciona até os dias atuais, foi localizado em seu acervo um grupo de imagens (fotografias originais). Tais fotos, embora não tenham sido produzidas pelo governo municipal, representaram o ideário republicano da época e, notadamente, do governo em que o grupo escolar foi fundado. O presente artigo dedica-se à analise desse grupo de imagens, tendo em conta o que essa escola representou nessa gestão municipal.

Para a elaboração dessa pesquisa foram utilizadas como fontes, além das fotografias do Grupo Escolar Dr. Joaquim Assumpção, os jornais pelotenses Diário Popular e o Libertador, os quais são fontes relacionadas, respectivamente, ao Partido Republicano e ao Partido Libertador e que apresentavam o contexto político e educacional e as singularidades locais durante a Primeira República.

Apesar de este artigo ser um estudo pontual sobre imagens de uma instituição escolar específica, pode-se, a partir delas, inferir sobre características do ideário republicano nacional e gaúcho, no que tange às instituições escolares e às práticas escolares. Além disso, deve-se ter em conta que a importância da categoria história local e regional cresceu substancialmente, seja como forma de construção das identidades locais, ou de percepção de similaridades entre a história local e a nacional.

Com relação à metodologia utilizada para abordar as fotografias, o trabalho com imagens foi feito com base na categorização das fotografias do arquivo do Grupo Escolar Dr. Joaquim Assumpção, tendo em vista que não foi necessária a sua organização por ordem cronológica, pois todas foram, aparentemente, produzidas no mesmo período. As categorias em que as imagens foram divididas são: inaugurações de retratos, apresentações de Educação Física, exposição de trabalhos manuais e corpo docente.

Deve-se ter em conta, também, que se buscou referenciais que embasassem o presente artigo. As fotografias encontram-se impregnadas de símbolos e mensagens. Segundo Leite, para a história o que interessa na fotografia implica "o ângulo de quem observa, analisa e tenta compor fotografias já existentes. Não é uma prática para quem escolhe a imagem, nem para o fotógrafo”, (LEITE, 1993, p.72). Além disso, conforme Dubois (1993), toda reflexão sobre um meio qualquer de expressão deve se colocar a questão fundamental da relação específica existente entre o referente externo e a mensagem produzida por esse meio. Trata-se da questão dos modos de representação do real ou, se quisermos, da questão do realismo. Fabris (1991) relembra Proust em sua 
afirmação de que a fotografia cria uma visão do mundo a partir do mundo, molda um imaginário novo, uma memória não-seletiva porque cumulativa. Em sua superfície o tempo e o espaço inscrevem-se como protagonistas absolutos, não importa se imobilizados, ou até melhor se imobilizados porque passíveis de uma recuperação, feita de concretitude e devaneio, na qual a aparente analogia se revela seleção, construção, filtro.

Com relação às fotografias de escolas e práticas escolares, Souza (2001) afirma que essas constituem um gênero muito difundido, a partir do século XX, combinado com outros gêneros como os retratos de família, as fotografias de paisagens urbanas, de arquiteturas e os cartões-postais. Além disso, a autora afirma que o surgimento e difusão desse tipo de fotografia vincula-se à disseminação do valor social da escola na sociedade brasileira e que, ao lado dos colegas, do professor ou da professora e às vezes do diretor, cada aluno e a classe enquanto coletivo simbolizam o próprio sentido social e cultural da escola.

A seguir, apresentar-se-á uma breve contextualização do Grupo Escolar Dr. Joaquim Assumpção, para que fique esclarecida a sua importância para o governo municipal. Após, serão abordadas as fotografias de inauguração de retratos. Posteriormente, serão analisadas as fotografias de apresentações de Educação Física, da exposição de trabalhos manuais e, por fim, do corpo docente.

\section{O Grupo Escolar Dr. Joaquim Assumpção}

Durante o governo de Augusto Simões Lopes foram criadas várias escolas rurais e dois grupos escolares urbanos (Dr. Joaquim Assumpção e Dona Antonia). Tanto o Dona Antonia, como o Dr. Joaquim Assumpção, foram construídos para serem os grupos escolares modelo da cidade de Pelotas. A divulgação quando do surgimento da idéia da sua construção foi muito grande. Porém, com o tempo, o último acabou por ganhar muito mais visibilidade e consolidou-se como a principal escola municipal construída no governo Simões Lopes. Como exemplo disso, pode-se citar a matéria do jornal Diário Popular:

\footnotetext{
Ainda ha pouco, de passagem por Pelotas, e visitando aquelle Grupo, em companhia do nosso illustre amigo dr. Augusto Simões Lopes, operoso intendente e benemerito reorganizador da instrucção, o sr. dr. Faria Netto, alto funccionario do ensino publico em São Paulo, em excursão de estudo pelo nosso Rio Grande, teceu francos elogios áquelle edifício e ás suas excellentes condições de hygiene, que disse não existirem melhores no seu Estado, mostrando-se até admirado que o Município, dentro de suas forças orçamentárias levasse a cabo obra de tal magnitude, (D. P., 10.08.1927).
}

Em Pelotas, as escolas estavam divididas em categorias, organizadas pelo "Regulamento da Instrucção Municipal", segundo o qual a aprendizagem elementar foi dividida, então, em três graus: o básico, o médio e o integral. O primeiro seria fornecido nas aulas isoladas, na cidade e na campanha, no qual a criança entraria em contato com os primeiros conhecimentos. Desse período inicial passava o aluno ao segundo estágio, restrito ainda, mas amplificado. Nesse momento, as matérias não aumentavam em número, mas em profundidade, o que tinha como intuito aguçar-lhe a curiosidade natural. Desse tipo, eram as Escolas Municipais Dr. Piratinino de Almeida e Barões de Santa Tecla, inauguradas, também, no governo de Augusto Simões Lopes. O último período de ensino primário elementar era oferecido pelas escolas integrais, nas quais, além de rememorar os seus estudos, os alunos preparar-se-iam para o ensino secundário. Esse estágio deveria ser 
oferecido nos dois grupos escolares urbanos, construídos nessa época: Dr. Joaquim Assumpção e Dona Antonia.

É possível afirmar que essa instituição escolar representou uma competitividade entre o governo municipal e o estadual, expressa por meio de inúmeras matérias na imprensa sobre o desenvolvimento da cidade de Pelotas e sobre como esta deveria ser seguida como modelo para as iniciativas do governo estadual e para outras cidades do estado.

O Grupo Escolar Dr. Joaquim Assumpção representava uma alternativa do ensino municipal em relação aos Colégios Elementares Félix da Cunha e Cassiano do Nascimento, ambos estaduais. A idéia de que o grupo escolar modelo municipal seria mais moderno, mais preparado, construído para atender a todas as necessidades apontadas pela pedagogia moderna, está bastante presente na imprensa, apresentando-se o ensino municipal como mais bem preparado do que o estadual. O Grupo Escolar Dr. Joaquim Assumpção teve, então, a responsabilidade de concorrer com dois colégios elementares já constituídos há mais tempo em Pelotas, com mais de uma década de existência. A escola preconizava o moderno, ao mesmo tempo em que, os seus próprios signos de modernidade representavam a manutenção da tradição. Tradição, essa, de Pelotas ser uma cidade de vanguarda.

Mesmo não se tratando de fotografias oficiais do governo Simões Lopes, deve-se ter em conta que essas imagens do arquivo do Grupo Escolar Dr. Joaquim Assumpção também possuem uma relação intrínseca com aqueles que contrataram a sua produção. Além disso, deve-se ter em conta que, conforme Leite, "quando inseridas em álbuns, vistas apenas pelos que as conservam e contemplam, estas fotografias têm um sentido muito diverso daquele que adquirem quando publicadas em revistas ilustradas ou almanaques", (LEITE, 1993, p.160). Embora essas imagens, conforme já afirmado, não tenham sido produzidas pelo governo Simões Lopes, elas referem-se à instituição considerada modelo e, logo, foram preservadas, provavelmente, por representar as melhores lembranças do estabelecimento. Segundo Le Goff:

O documento não é qualquer coisa que fica por conta do passado, é um produto da sociedade que o fabricou segundo as relações de forças que aí detinham o poder. Só a análise do documento enquanto monumento permite à memória coletiva recuperá-lo e ao historiador usá-lo cientificamente, isto é, com pleno conhecimento de causa, (LE GOFF, 1992, p.545).

Além disso, o recorte temporal desta pesquisa (década de 1920) é marcado por um período em que a maior parte das fotografias era produzida por profissionais. Esta diferença é completamente perceptível no montante do arquivo que inclui fotografias mais atuais, as quais não possuem a mesma técnica que as da época de sua inauguração (além, é claro, das diferenças no material utilizado).

Outro ponto que deve ser levado em consideração é o fato de que, antes mesmo de ter sido inaugurado, o Grupo Escolar Dr. Joaquim Assumpção já ser considerado a maior promessa da gestão de Augusto Simões Lopes, pela grandiosidade do prédio projetado e pelas condições de ensino que se pretendiam oferecer. Logo, as fotografias, que provavelmente foram produzidas entre 1927 e 1928, procuram, ao máximo, demonstrar o ambiente glorioso que ali se constituía. As imagens desse arquivo permitem, também, conhecer um pouco mais das práticas escolares descritas muitas vezes nos jornais, mas raramente representadas, visto que a maior parte das fotografias oficiais do governo municipal era de prédios escolares. 


\section{As inaugurações de retratos:}

As imagens de inauguração de retratos de patronos e do intendente não foram publicadas na imprensa, ficando relegadas aos arquivos particulares da escolas, o que, muitas vezes, ocasionou a sua perda. A existência desse tipo de fotografias é comprovada com base no arquivo fotográfico do Grupo Escolar Dr. Joaquim Assumpção, no qual temos a imagem da festa de inauguração dos retratos do patrono e do intendente. Provavelmente o caráter desse tipo de comemoração fosse bastante íntimo, contando apenas com uns poucos convidados que estavam relacionados com a vida da própria escola. Ou, ainda, a sua relevância política não era tão grande. Fundamentalmente, as fotografias do arquivo desse grupo escolar, mesmo que oficiais, são imagens institucionais, cujo intuito maior é preservar a memória de uma instituição, sem promover, de certa forma, a propaganda de um governo. Mesmo que isso não ocorra, as fotografias de uma instituição devem ser, também, percebidas com certa desconfiança. Certamente o fato de serem fotografias originais e não imagens impressas, dificulta pequenas alterações. Também, deve-se dizer, que o fato de não terem sido produzidas com o intuito de serem difundidas na imprensa demonstra que o seu vínculo era maior com a instituição que as produziu do que com os interesses do intendente municipal. Ainda assim, fotografias de instituições procuram sempre mostrar o que existe de melhor nelas próprias, eternizando momentos importantes (a inauguração de retratos), os quais foram selecionados para permanecer na memória institucional.

No arquivo fotográfico do Grupo Escolar em estudo encontram-se duas fotografias de "inauguração de retrato". A primeira (figura 1 - aliás, a primeira fotografia do álbum, antecedida apenas por uma reprodução da fotografia da escola extraída do Almanach de Pelotas), é a imagem da inauguração do retrato do patrono, o próprio Joaquim Assumpção. A ausência de referência às personagens ali representadas, não permite a identificação de todos. Isso pode ser explicado pela afirmação de Souza (2001), que aponta para o fato de, na memória das escolas públicas, as fotografias inscrevem-se na imanência do tempo presente, nos acontecimentos significativos para professores, alunos e funcionários partícipes dessa temporalidade do agora, e assim, ela se constitui em um instrumento de memória institucional e de recordação, e poucas vezes, como instrumento de história. Para essa autora, o anonimato, a ausência de datas e nomes que as identifiquem são indicativos de uma funcionalidade que se inscreve na ordem afetiva dos significados compartilhados e escapa à lógica do documento e do arquivo.

Ao centro da imagem, encontra-se o retrato do patrono, tendo à sua direita um grupo formado por três homens, dos quais o primeiro é Augusto Simões Lopes e o segundo, provavelmente, João Brum de Azeredo, que era o Diretor da "5. Directoria", responsável pela instrução pública. Do lado esquerdo do retrato, formou-se um grupo que contava, também, com três mulheres, acarretando uma certa simetria à imagem, intencional ou não. A primeira delas é, provavelmente, a diretora da escola ou a Dona Maria Francisca Mendonça de Assumpção, viúva do patrono e que, com seus donativos (em dinheiro e do terreno) possibilitou a construção do Grupo Escolar. Acredita-se que as mulheres representadas na imagem eram ou parentes do patrono ou professoras da escola. O caráter de formalidade do acontecimento torna-se perceptível por meio da postura que as personagens assumem e das vestimentas elegantes que usam.

Conforme matéria do jornal o Libertador, a inauguração do retrato do patrono ocorreu no mesmo dia da inauguração do Grupo Escolar. Sobre isso, lê-se: 
Quer sob o ponto de vista da instrucção, quer sob o aspecto social, foi uma festa de muito brilho a inauguração, hontem, do Grupo Escolar dr. Joaquim Assumpção.

Vimos ali, alem do mundo official, um numeroso grupo de senhoras e cavalheiros de nossa melhor sociedade, emprestando, com sua presença, uma significação expresiva do acto e, ao mesmo tempo, homenageando a memória do distincto pelotense probo e bom, que foi o dr. Joaquim Augusto de Assumpção, (O L., 1. ${ }^{\circ}$ de agosto de 1927).

Por meio desse trecho, percebe-se um certo caráter elitista da cerimônia (verificado na fotografia pelos trajes elegantes), que contava com a presença da "melhor sociedade". Além dessas informações, a matéria do jornal o Libertador descreveu o ato de inauguração do retrato, apontando detalhes sobre a cerimônia:

Ás 11 horas, cheias todas as dependências do vasto edifficio, construído e caprichado para o fim a que se destina, por administração, com distinctas linhas achitectonicas, muito gosto, todo o conforto e as melhores disposições hygienicas - o sr. dr. Augusto Simões Lopes, intendente do município, descerrou a cortina sob a qual na entrada do edifficio se achava um excellente retrato do patrono do estabelecimento, (O L., 1. ${ }^{\circ} \mathrm{de}$ agosto de 1927).

Figura 1 - Inauguração do Retrato do Patrono do Grupo

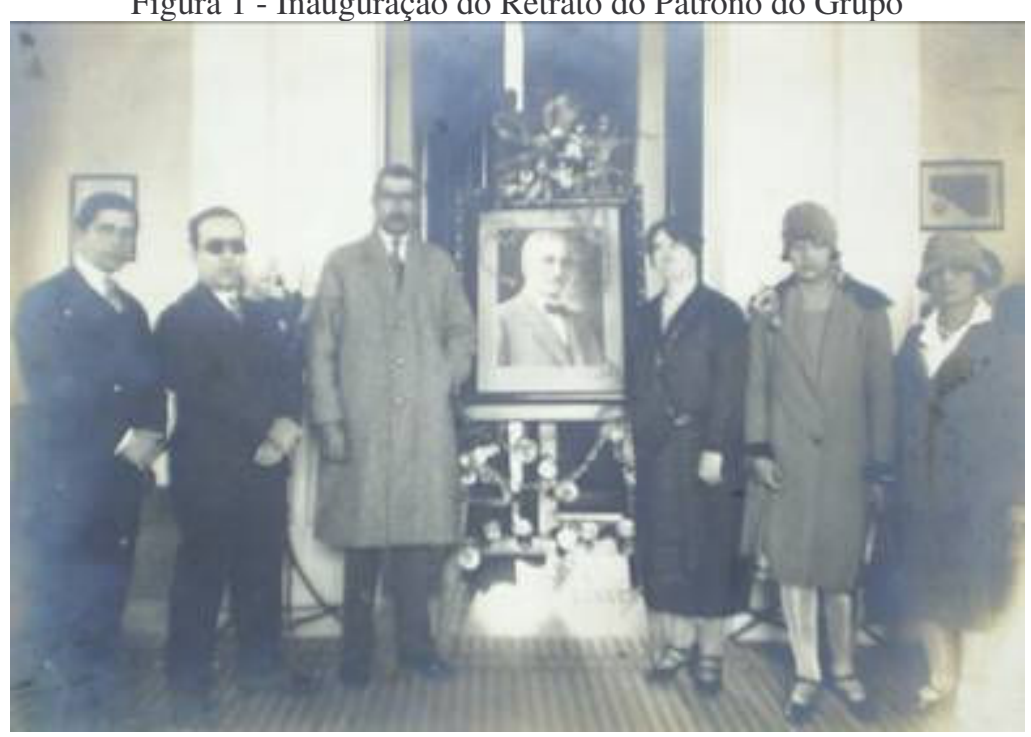

Fonte: Arquivo do Grupo Escolar Dr. Joaquim Assumpção

A segunda imagem (figura 2), seguindo a ordem estabelecida no álbum da escola, refere-se à inauguração do retrato de Augusto Simões Lopes. Tal como a anterior, a fotografia não apresenta informações sobre as pessoas ali presentes. Acredita-se que essa inauguração tenha ocorrido posteriormente à primeira. Alguns motivos levam à referida conclusão. Primeiro, os organizadores do álbum aparentemente levaram em consideração para a montagem do álbum critérios cronológicos (embora seja possível que, por desinformação, algumas fotografias encontrem-se em locais inadequados). Segundo, as vestes da primeira fotografia são bastante pesadas, caracterizando a fotografia como produzida em um mês de inverno, na segunda imagem, as pessoas (e isso fica mais claro nas roupas femininas) apresentam vestimentas mais leves (o próprio Augusto Simões Lopes - à esquerda do retrato - não aparece vestindo o seu sobretudo cinza da fotografia da 
inauguração do retrato do patrono). Terceiro, a presente imagem conta com a presença de alguns alunos. E, finalmente, pode-se dizer que se costumava inaugurar o retrato do patrono logo da inauguração da própria escola, o que partia, em geral, do governo municipal (praticamente todas as escolas ostentavam os retratos de seus patronos, na Escola Bibiano de Almeida isso ainda pode ser percebido). O retrato do intendente, ao contrário, partia, de acordo com informações extraídas de jornais da época, da população local ou da comunidade da escola, que decidia, então, homenagear aquele que criou o estabelecimento de ensino. Como exemplo disso, pode-se citar a matéria sobre a inauguração do retrato de Augusto Simões Lopes nas Escolas Dr. Piratinino de Almeida e Barões de Santa Tecla:

Numa alta demonstração do quanto as populações do Areal e do Capão do Leão se acham satisfeitas com o programma de instrucção popular benemeritamente desenvolvido pelo operoso intendente municipal, nosso amigo, dr. Augusto Simões Lopes, que criou há cerca de um anno naquellas localidades duas magníficas escolas, respectivamente a de nome Piratinino de Almeida e a intitulada Barões de Santa Tecla, vai ser collocado na ampla sala de aulas daquellas duas escolas pelos moradores de ambas as povoações o retrato do illustre edil, (D.P., 30 de abril de 1927).

Figura 2 - Inauguração do retrato de Augusto Simões Lopes

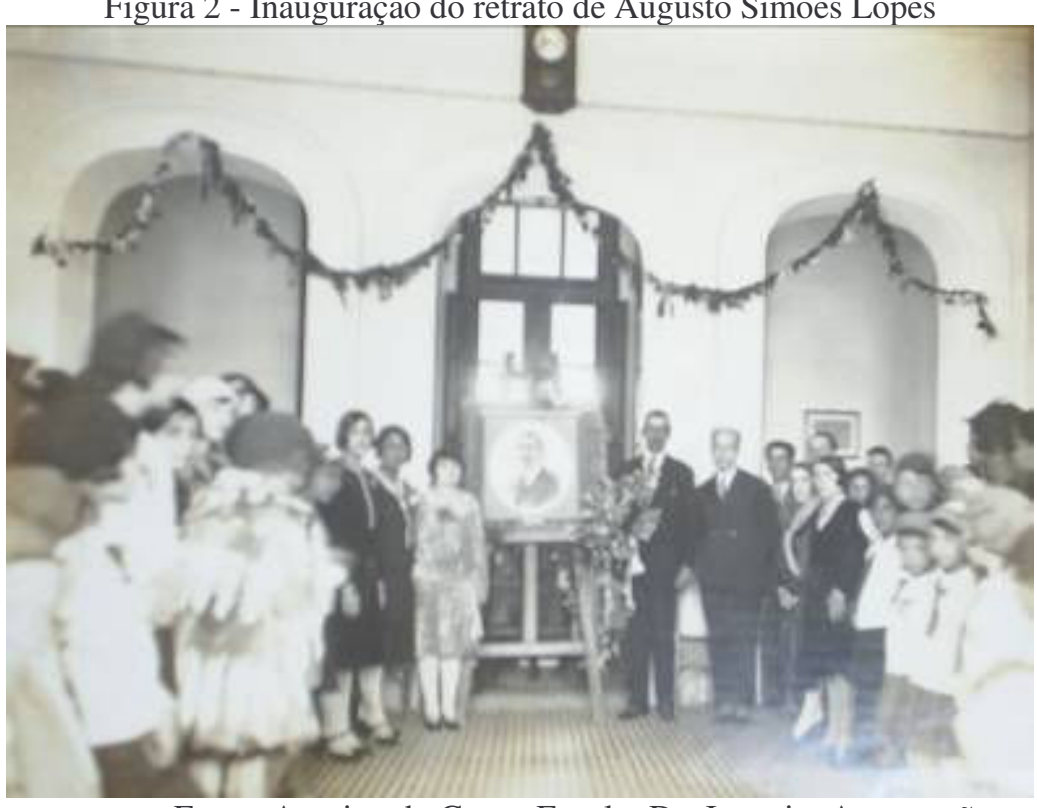

Fonte: Arquivo do Grupo Escolar Dr. Joaquim Assumpção

É bastante difícil confirmar se essa prática partia realmente das populações, como afirma o jornal Diário Popular, ou se era uma forma de o intendente perpetuar a sua imagem dentro dos institutos de ensino estabelecidos por ele. Alves (1998) afirma que o poder político de governo, no seu exercício habitual de mobilização de forças para reconhecimento pelos profanos (em nome de quem, deixa entrever, fala e faz), formaliza permanentemente sua apropriação por meio de visitas, inaugurações e reinaugurações, bem como de organização do lugar. Para ela, o capital político, enquanto poder simbólico, mobiliza a todos aqueles que vão ocupar aquele espaço feito lugar, tanto a população que vai colocar seus filhos na escola (e que vai estar lá como funcionário, aluno, pai) como aqueles profissionais que nela vão trabalhar. Dessa forma, percebe-se que a presença, seja 
nas festividades ou por intermédio do retrato observado diariamente na vida cotidiana da escola, permite uma verdadeira apropriação do espaço, reafirmando para aqueles que estavam ligados à instituição, o caráter de "benemerência" do intendente. Borges (2003) aponta, sobre o hábito da confecção de retratos de indivíduos:

Parte significativa da fotografia, profissional e/ou amadora, passou pela confecção de retrato de indivíduos cujo desejo era transcender os muros do anonimato erigidos pelo ritmo acelerado e voraz da modernidade. Desde cedo o retrato fotográfico se coloca como uma prova material da existência humana, além de alimentar a memória individual e coletiva de homens públicos e de grupos sociais. Não por acaso, antes de deixar o país rumo ao exílio, a família imperial doou à Biblioteca Nacional sua imensa coleção de fotografias, (BORGES, 2003, p.41).

Além disso, a autora afirma que:

As linhas de fuga dos retratos, quase sempre a meio-corpo, atraem o olhar dos expectadores para os detalhes da roupa, das mãos e da expressão do seu olhar. O fotógrafo-artista quer, fundamentalmente, exprimir uma tese corrente no mundo da pintura, na qual o retrato artístico mais que informar, deveria representar. Ou seja, "condensar em uma imagem simbólica o essencial das qualidades e das funções de um indivíduo importante", (Ibidem, 2003, p.44).

Além das questões que envolvem as cerimônias de inauguração de retratos, a segunda imagem desse grupo, possui em seu conteúdo (possivelmente de forma não intencional), uma das características mais comuns em grupos escolares: o relógio. De acordo com Faria Filho (1996), não bastava o ordenamento espacial para afirmar a representação de cultura escolar trazida pelos grupos escolares. Num meio onde a escola era, até então, uma instituição que se adaptava à vida das pessoas (as escolas isoladas tinham os seus espaços e horários organizados de acordo com a conveniência da professora e dos alunos, levando em conta os costumes locais), tornava-se necessário algo mais do que produzir um espaço para a educação: precisava-se, também, que novas referências de tempos e novos ritmos fossem construídos e legitimados.

Segundo esse autor, as aulas passaram a cumprir horários determinados, o que levou a instrumentos como os relógios, as campainhas e as sinetas a fazerem parte do material básico dos grupos escolares. Conforme Souza (1996), na escola a criança internalizava as primeiras percepções cognitivas da temporalidade, pautadas na exatidão, na aplicação e na regularidade; noções de um tempo cronometrado, útil, que era preciso aproveitar. Em sendo, portanto, um instrumento de ordenamento temporal, o relógio ocupa um lugar central no saguão da escola, onde todos os alunos, professores e funcionários do Grupo Escolar Dr. Joaquim Assumpção, poderiam vê-lo.

\section{As apresentações dos alunos de Educação Física: um ritual cívico:}

As fotografias que se seguem às anteriores referem-se à prática da Educação Física e ao grupo de escoteiros. Infelizmente, esse grupo de três imagens foi o que mais sofreu com o passar do tempo: esmaeceram e, especialmente a primeira delas, por ser uma fotografia tirada de uma distância maior, em um espaço com grande incidência de sol, perdeu muito de sua nitidez. Mesmo com as dificuldades causadas pelo estado de conservação das fotografias, pode-se extrair desse grupo muitas informações sobre a 
prática da educação física como uma forma de disciplina e como um ritual cívico e público.

De acordo com Souza (2000), nas últimas décadas do século XIX, a educação popular adquiriu centralidade política como nunca tivera antes no Brasil. Ela foi considerada o elemento de regeneração da nação, um instrumento para a reforma social e a propulsora do progresso e da civilização. A educação do povo compreendia, portanto, um amplo projeto político-social e uma bandeira de luta para monarquistas e conservadores, e, especialmente, para liberais e republicanos.

Segundo Hilsdorf (2005), a educação pelo voto e pela escola foi instituída pelos republicanos como a grande arma da transformação evolutiva da sociedade brasileira, e assim oferecida em caução do progresso prometido pelo regime republicano: a prática do voto pelos alfabetizados e, portanto, a freqüência à escola, que formaria o homem progressista, adequado aos tempos modernos, é que tornariam o súdito em cidadão ativo. Fossem liberais, democráticas ou conservadoras, as forças políticas movimentaram-se para controlar as instituições educativas e seus agentes e impor-lhes, de modo definitivo, a forma escolar como a mais adequada e eficaz para ministrar e conformar a sociedade.

Na primeira fotografia do grupo (figura 3), em primeiro plano, na parte de baixo da imagem, encontra-se um grupo de pessoas voltadas para um número muito grande de alunos uniformizados, formado especialmente por meninas. Pode-se perceber que o local retratado é o próprio pátio da escola. Atrás dos alunos parados, em posição de sentido, demonstrando ordem e disciplina (princípios fundamentais da Educação Física, naquele período), nota-se a presença de uma grande bandeira. A disciplina de Educação Física esteve muito relacionada com as apresentações de alunos em datas nacionais ou regionais (7 de setembro, 20 de setembro, etc.). Além disso, Augusto Simões Lopes apontou sobre essa disciplina presente no currículo escolar: "Cuidados mereceu a educação physica, tornando obrigatória, como factor de eugenia mundialmente preconizado”, (R.I. de 1927, p.218). De acordo com Souza (1996), a Educação Física era destacada pela sua influência moralizadora e higiênica. Por intermédio dela, os corpos tornar-se-iam ágeis, fortes, robustos e vigorosos, ela desenvolveria a coragem e o patriotismo. Para a autora, esse investimento no corpo dos indivíduos os situaria nos ideais de moralização e ordenação social.

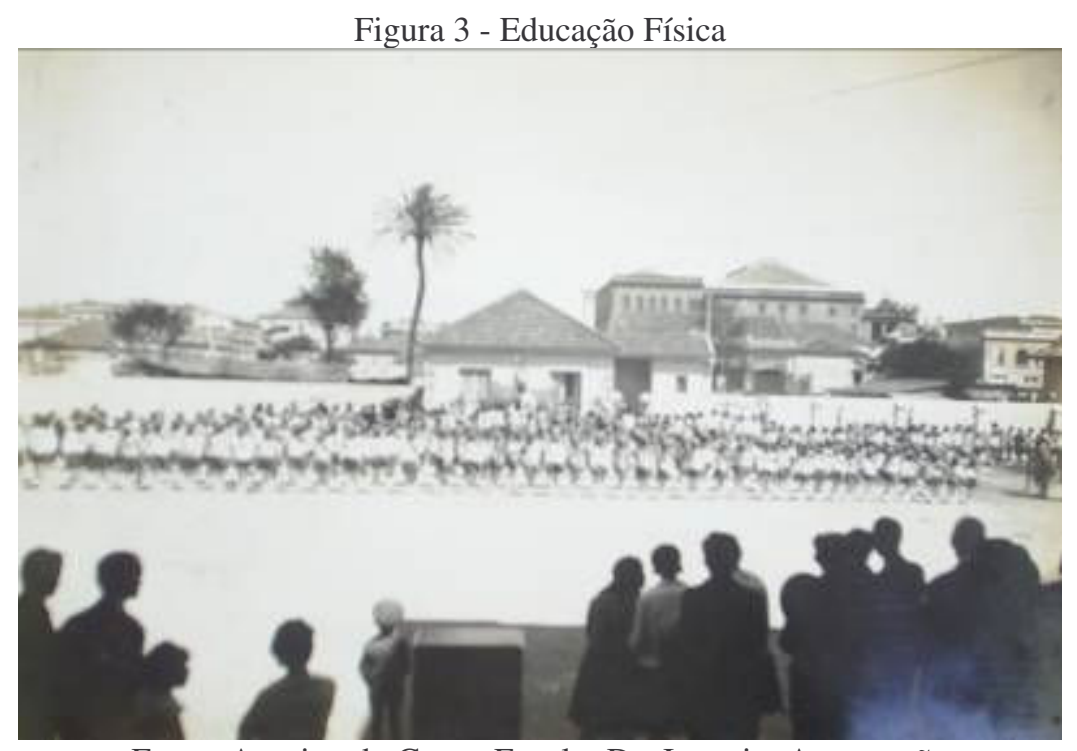

Fonte: Arquivo do Grupo Escolar Dr. Joaquim Assumpção 
A matéria do dia $1 .^{\circ}$ de setembro de 1928, do jornal Diário Popular, reafirma esse caráter da Educação Física e os cuidados que ela mereceu durante o governo Simões Lopes:

Grandes cuidados mereceu a educação physica e moral. São resultados do pensamento superior de desenvolver amplamente o aperfeiçoamento do corpo e do caracter a criação dos cursos especiais de gymnastica pedagogica, entregue a um profissional meritoso e a instituição do escotismo, que actualmente congrega quase todos os alumnos acima de 9 annos, (D.P., $1^{\circ}$ de setembro de 1928).

A segunda fotografia do conjunto (figura 4) é uma espécie de continuação da primeira. Nela, um grupo de alunas, dividido em diversas fileiras, apresentam exercícios. Além disso, como se supõe que a fotografia foi tirada de uma das janelas do pavimento superior do Grupo Escolar Dr. Joaquim Assumpção, o ângulo permite ao observador notar a formação que os meninos, com o seu uniforme de escoteiro, apresentam, formando duas colunas de cada lado da bandeira (que na imagem pode ser definida como a bandeira nacional). Pode-se perceber que, em se tratando da disciplina de Educação Física, existe uma divisão por sexo. De acordo com Souza (1996), que pesquisou a formação dos grupos escolares em São Paulo, era somente nos trabalhos manuais e na ginástica que a organização mantinha a diferenciação por gênero.

Em relação à Educação Física, Souza (2000) afirma que o republicano Rui Barbosa construiu seus argumentos com base no princípio da educação integral - Educação Física, intelectual e moral -, apelando para a indissociabilidade entre corpo e espírito e para a necessidade do processo educativo seguir as mesmas leis da natureza. Para a autora: "Nas representações de Rui sobre os benefícios da Ginástica na educação popular, emergem as funções morais, cívicas, disciplinadoras e higiênicas que foram atribuídas a esse ensino no século XIX”, (SOUZA, 2000, p.107).

A última fotografia do conjunto (figura 5), sob a legenda de "Grupo de Escoteiros" refere-se, ainda, à mesma comemoração, pois parece possível afirmar que é ainda o mesmo grupo de alunos e a mesma bandeira nacional. Essa fotografia também parece ter sido tirada do pavimento superior do prédio, permitindo a observação das três fileiras frontais, formada pelas alunas; das colunas que ladeiam a bandeira e de uma fileira de alunos próximos do muro.

Tal conjunto de imagens refere-se, possivelmente, a uma das várias comemorações cívicas realizadas na escola e divulgadas na imprensa, especialmente no jornal Diário Popular, como por exemplo, na matéria sobre uma festa em 20 de setembro: "Este collegio commemora brilhantemente a grande data de 20 de Setembro, que hoje transcorre. Os alumnos apresentar-se-ão com o novo e bem talhado uniforme em numero de cerca de 140”, (D.P., 20 de Setembro de 1927). 


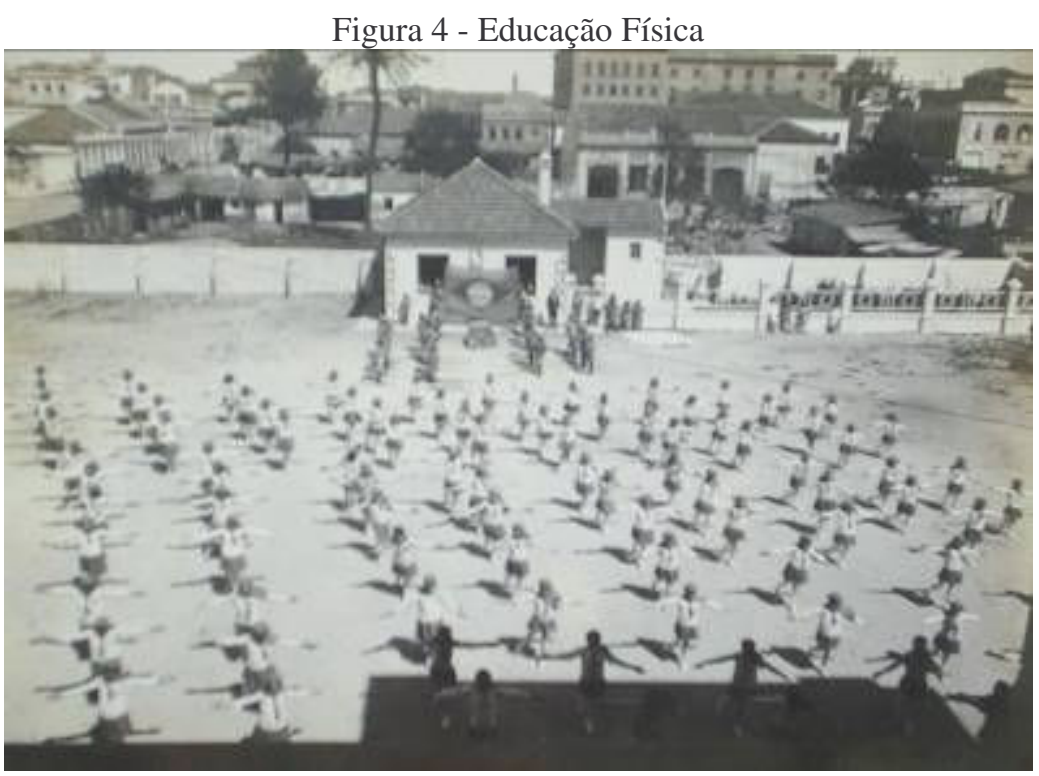

Fonte: Arquivo do Grupo Escolar Dr. Joaquim Assumpção

Figura 5 - Grupo de Escoteiros

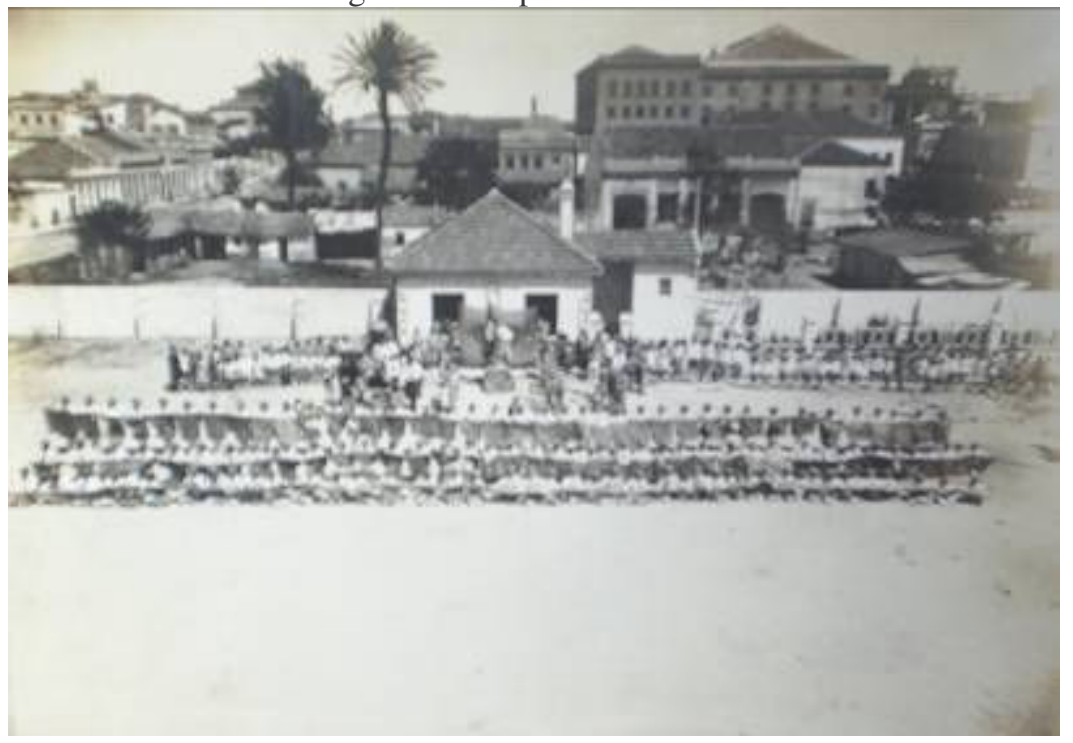

Fonte: Arquivo do Grupo Escolar Dr. Joaquim Assumpção

Embora não se possa afirmar, as fotografias desse conjunto podem até se referir a essa comemoração de 20 de setembro. Mas, sendo ou não, as comemorações cívicas eram um costume vigente. Conforme Corsetti (1997), os rituais, expressos por meio das comemorações e festas cívicas, destinadas à propaganda eficiente dos valores da modernidade republicana, foram um instrumento de construção do imaginário social no Rio Grande do Sul. As festas escolares eram verdadeiros rituais destinados a modelar condutas. O caráter desses encontros não era apenas laudatório das personalidades mitificadas, mas serviam, também, para estimular condutas positivas, reforçando os comportamentos recomendados com o estímulo de premiações, as quais eram distribuídas aos alunos de melhor desempenho.

A utilização de símbolos, para essa autora, é muito peculiar na caracterização dos meios utilizados para a construção do imaginário republicano, por meio da escola. A simbologia teve, no hino e na bandeira (presente nas três imagens), suas duas maiores 
expressões, representando a identificação instantânea dos valores da República. Corsetti aponta que:

\begin{abstract}
Assim, manipulando símbolos e mitos, utilizando-se dos rituais cívicos, os positivistas gaúchos envolveram particularmente a escola pública, para alicerçar os valores indispensáveis à adesão da sociedade ao seu projeto de desenvolvimento do Estado. A política educacional da época, portanto, jogou com a subjetividade inerente ao processo de construção da consciência coletiva, em paralelo ao desenvolvimento bastante objetivo que davam à modernização conservadora do Rio Grande, (CORSETTI, 1997, p.278).
\end{abstract}

Além disso, percebe-se nas imagens a relação da Educação Física com o escoteirismo e desse com o Grupo Escolar Dr. Joaquim Assumpção. A escola pública, utilizada como meio conformador por intermédio de seus símbolos, das disciplinas e de seu próprio espaço, tem no escoteirismo uma das práticas que mais evidencia a relação com a formação cívica do aluno. Em matéria do jornal Diário Popular, afirmava-se sobre a presente escola:

Dest'arte, esse novel collegio, legítimo orgulho da instrucção municipal, marca os seus primeiros passos com uma forte atuacção no nosso meio social. Na pedagogia moderna, o escoteirismo é uma instituição magnífica de educação popular, pois ela é uma escola pratica e brilhante de exemplos de moralidade, de trabalho e civismo. Que mais bela missão pode ambicionar a escola moderna do que preparar cidadãos dignos, patriotas e dotados de um forte sentimento de humanidade? Só palavras merecem o collegio Dr. Joaquim Assumpção, por tão bela iniciativa", (D.P., 12 de outubro de 1927).

Deve-se ter em conta, também, que mais do que apenas uma escola primária, o Joaquim Assumpção era um grupo escolar, a típica escola republicana. Para Faria Filho (1996), os grupos escolares significavam mais do que uma forma de organizar a educação, mas, fundamentalmente, uma estratégia de atuação no campo do educativo escolar, moldando práticas, legitimando competências, propondo metodologias, enfim, impondo uma outra prática pedagógica e social dos profissionais do ensino por intermédio da produção e divulgação de novas representações escolares.

O grupo escolar como divulgador do ideário republicano, constituído em seu espaço próprio, possui uma marca, um limite: o muro. Esse delimita o lugar que a educação ocupa na cidade. Nas três fotografias pode-se perceber a presença desse, separando a escola do âmbito urbano que a envolve. Segundo Faria Filho (1996): "o muro configuraria, simbólica e materialmente, a delimitação de um espaço próprio, apartado da rua e que se auto-institui como significativo, ao mesmo tempo em que produz aquela como lugar maléfico às crianças", (FARIA FILHO, 1996, p.118). Além disso, para o autor, a busca em separar a escola da rua, implicou, também, a criação do pátio escolar, considerado um espaço de transição, que significava a passagem de uma ordem a outra, de uma cultura a outra. Esse autor afirma, também, que o muro era inexistente nas escolas isoladas e, ao observar as imagens das escolas rurais, percebe-se que várias delas não possuem muro, enquanto outras já o apresentam, passando a configurar-se em escolas institucionalizadas, separadas do âmbito externo.

Outro aspecto que pode ser comparado com o conjunto de imagens de escolas rurais é a questão do uniforme. Em fotografias do conjunto produzido pelo governo Simões 
Lopes, que representam escolas rurais, entre as poucas em que alunos são retratados, percebe-se que os alunos vestiam as suas próprias roupas. É claro que se deve ter em conta que se tratam de escolas subvencionadas e, como já foi dito, existia uma hierarquia entre as escolas sendo que as subvencionadas ocupavam um dos patamares mais baixos. Os alunos do Grupo Escolar Dr. Joaquim Assumpção, ao contrário, ostentavam o seu uniforme, que mereceu ser citado no jornal Diário Popular: "Os alumnos apresentaram todos o novo uniforme, os meninos, a escoteiro, e as meninas envergando vistosos e elegantes trajes, que dava ao conjuncto da formatura um alegre aspecto, numa impressão de bom gosto e disciplina", (D.P., 22 de setembro de 1927). O uniforme escolar pretende esconder qualquer diferença social, percebida apenas pelos sapatos.

\section{A exposição de trabalhos manuais:}

Entre as mais antigas fotografias do arquivo do Grupo Escolar Dr. Joaquim Assumpção, encontra-se uma referente a uma exposição de trabalhos manuais (figura 6). Nessa imagem, tem-se retratada uma das salas da escola. Na parede estão presentes vários quadros e mapas, cuja maioria, provavelmente, referia-se a outras disciplinas. Além disso, vários móveis, especialmente mesas e algo semelhante a uma cama, estão representados na medida em que foram utilizados como suporte para a exposição de toalhas de mesa, colchas, almofadas, entre outros utensílios bordados. Nesta fotografia, tem-se a representação do fruto das aulas de trabalhos manuais desse estabelecimento.

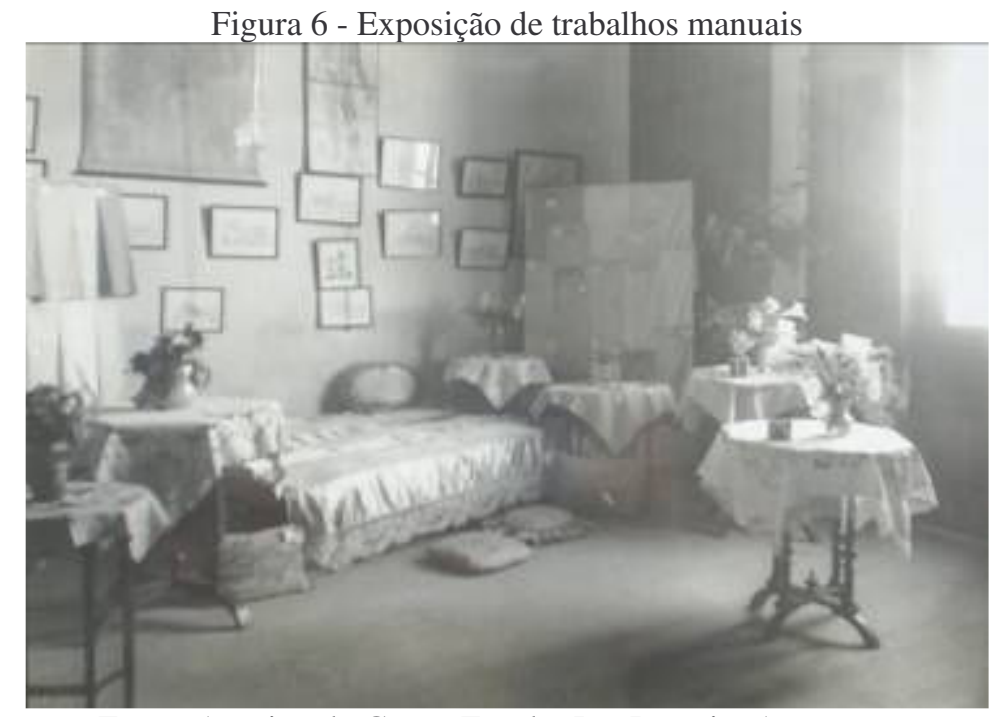

Fonte: Arquivo do Grupo Escolar Dr. Joaquim Assumpção

A disciplina de trabalhos manuais tornou-se obrigatória no currículo das escolas municipais, com base no "Regulamento da Instrucção". De acordo com Souza (1996), acreditava-se que por intermédio dos trabalhos manuais as crianças de todas as classes sociais aprenderiam a valorizar o trabalho manual. Para as crianças do povo, essa matéria significava a afeição ao trabalho, o início da aprendizagem de um ofício. De acordo com Corsetti (1997), o projeto político republicano envolveu a educação e o seu caráter profissionalizante como instrumento capaz de formar cidadãos prontos a se adequarem ao mercado de trabalho.

O Grupo Escolar Dr. Joaquim Assumpção foi, pela importância que alcançou, um dos estabelecimentos de ensino primário em que o "Regulamento da Instrucção" foi aplicado de forma mais intensa. Logo, retratar uma exposição de trabalhos manuais, realizada na escola, significa que esse era um tipo de acontecimento importante e que o 
corpo docente encontrava-se bastante satisfeito com os resultados da disciplina. A essa conclusão chegou-se devido ao fato de que, embora a fotografia já fosse algo mais acessível, ela ainda era produzida por profissionais, os quais eram contratados, em geral, para retratar momentos de significativa importância para as instituições.

Além disso, as exposições de trabalhos manuais não ocorriam somente no interior das escolas. Em 1927, a Seção Pelotense da Associação Brasileira de Educação promoveu uma exposição, na Bibliotheca Pública Pelotense, de trabalhos manuais, livros didáticos e material escolar, da qual participaram colégios particulares, estaduais e municipais, além de livrarias. Tendo-se em conta que os trabalhos realizados em aula iam a público nesse tipo de exposição, acredita-se que o Grupo Escolar Dr. Joaquim Assumpção, principal escola municipal de ensino primário, esforçava-se ao máximo para que suas alunas produzissem trabalhos realmente muito bons. Dessa forma, os trabalhos manuais ocupavam um espaço privado e um espaço público, participando do processo de valorização do ensino na referida escola.

\section{Uma fotografia de professoras:}

A última fotografia do arquivo do Grupo Escolar Dr. Joaquim Assumpção (figura 7) tem como legenda, no álbum do qual foi extraída, as palavras "corpo docente". Logo, acredita-se que ela retrate um grupo de professoras, provavelmente a primeira formação. $\mathrm{Na}$ frente, pode-se observar que cinco professoras encontram-se sentadas. Atrás e em pé, têm-se outras dez mulheres. Devido ao fato de, provavelmente, as legendas não terem sido preenchidas na mesma época em que as fotografias foram feitas, pode-se perceber, muitas vezes, a existência de informações incompletas. Talvez nem todas as mulheres ali retratadas fossem professoras, algumas poderiam ser funcionárias. Ou, mesmo que todas fossem professoras, nenhuma foi identificada. Não se sabe, por exemplo, se a diretora encontra-se entre o grupo, ocupando a posição central, ou se existe algum fator que determinou a ordem que cada uma delas ocupa na imagem. $\mathrm{O}$ mais provável é que não tenha existido um motivo que levasse à determinação dos lugares, além da necessidade de simetria, bastante presente nessa fotografia.

A existência desse tipo de imagem pode denotar, também, a importância que existe para a instituição em cristalizar na sua memória a lembrança de seus funcionários, por serem eles parte de sua história, ou, em sendo um colégio recém criado, para retratar aqueles que iriam participar da afirmação do Grupo Escolar Dr. Joaquim Assumpção como uma das escolas mais importantes da cidade. Nas fotografias oficiais do governo Simões Lopes, ao contrário, os professores não se tornaram o seu foco.

Embora o professorado tenha ocupado grande parte das preocupações presentes no "Regulamento da Instrucção", tais como o estabelecimento de concurso para o provimento das vagas urbanas e "exame de sufficiencia" para as rurais, cursos de aperfeiçoamento e de férias, etc., parece possível dizer que a utilização de imagens de professores não atingiria os expectadores tão intensamente como as imagens de prédios escolares. Uma fotografia de professores (com exceção de casos em que se conta com a presença de professores reconhecidos no município) não permite ao observador perceber se a qualidade buscada pelo Regulamento foi alcançada, se os professores aperfeiçoaram os seus conhecimentos e se foram ajustados às suas novas condições de trabalho.

Cabe ressaltar que a pesquisa que utiliza fotografias como fonte é bastante interessante no sentido em que permite comparar conjuntos fotográficos e, através disso, compreender não só o conteúdo presente na imagem, mas a sua ausência. Como já foi dito, as práticas escolares ocuparam um espaço muito restrito no conjunto de documentos fotográficos produzidos, talvez porque, tal como as fotografias de professores, elas não 
tivessem o mesmo apelo. Além disso, percebe-se que o objetivo das imagens, como estratégia de propaganda, foi o de traçar uma vista geral do ensino primário municipal. As fotografias que não se referem a prédios de escolas, incluídas no Relatório Intendencial de 1928, procuram fazer com que aquilo que elas representam pareça estar presente em qualquer escola municipal.

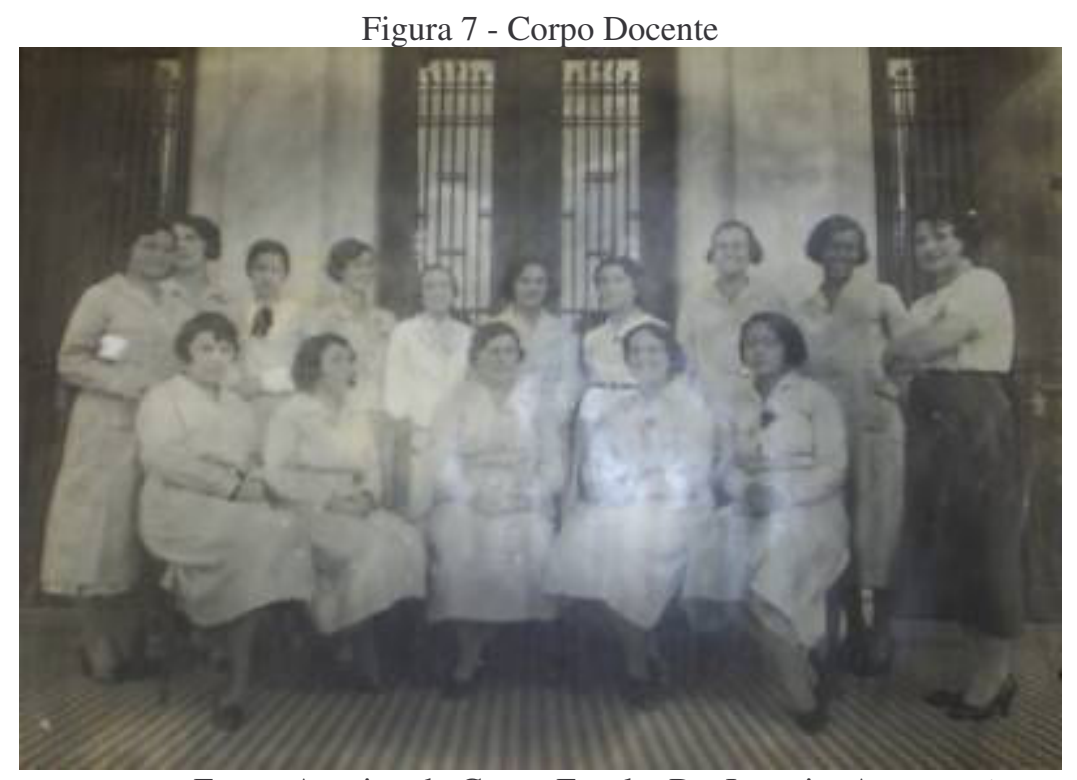

Fonte: Arquivo do Grupo Escolar Dr. Joaquim Assumpção

Pode-se dizer que esse tipo de imagem é bastante comum em acervos de instituições de ensino, que procuram retratar os seus professores (assim como ocorre, muitas vezes, com os alunos e funcionários). Além disso, o conteúdo dessa imagem demonstra que o Grupo Escolar Dr. Joaquim Assumpção possuía, na época, apenas professoras mulheres. Essa não era uma característica restrita a tal escola, pois, com base nos jornais da época, a maior parte das escolas municipais, inauguradas nessa gestão, foi entregue aos cuidados de diretoras e professoras. Segundo Faria Filho (1996), a quase totalidade do corpo docente dos grupos e das escolas isoladas era constituída de mulheres, assim como todas as ocupantes dos cargos de direção de Grupo. Eram homens os professores das aulas de ensino profissional e os inspetores.

De acordo com Corsetti (1997), no plano educacional, a figura feminina passou, no período republicano, a ser considerada a educadora por excelência. A mulher, no mercado capitalista, como professora, revelou o quanto ela foi usada para a manutenção de uma política salarial comprimida, que levou os homens à busca de novas alternativas profissionais, possibilitando uma política de expansão da educação a baixos custos.

Segundo Perrot (1988), a ação das mulheres no século XIX consistiu sobretudo em ordenar o poder privado, familiar e materno, a que eram destinadas. A administração do pagamento do marido seria em larga medida atribuída a ela, e sem dúvida essa é uma conquista feminina que implica poder, mas também aumento da responsabilidade e, em períodos de penúria, privação pessoal.

É possível perceber que essa fotografia insere-se em um período em que os homens praticamente abandonaram o magistério primário, que foi ocupado pelas mulheres. Conforme Almeida (2004), para as professoras primárias da primeira metade do século $\mathrm{XX}$, o magistério foi o ponto de partida, foi o possível no momento histórico em que viveram. Segundo ela, isso significou o trânsito do invisível para a visibilidade e a 
realização de algo que não fosse o único e prestigiado serviço doméstico. O exercício do magistério representava um prolongamento das funções maternas, e instruir e educar crianças era considerado mais do que aceitável, ideal, pela sua conduta moral e jeito com os alunos. O certo é que, quando o Grupo Escolar Dr. Joaquim Assumpção foi criado, o magistério primário já era eminentemente feminino.

De acordo com Bonato (2000), as Escolas Normais historicamente vem formando vários professores, mais mulheres do que homens, para o então ensino primário. Nesse sentido, Peres (2000) afirma que não se pode, ao discutir o processo de feminização do magistério, apontar uma causa única como responsável por esse fenômeno. Ele é resultado de um conjunto de elementos sociais, culturais e econômicos, decorrentes das transformações que se operam na sociedade na virada do século, e também de um conjunto de mudanças no próprio processo de escolarização (aumento das aulas para meninas, por exemplo).

Mais do que um grupo de professoras, a imagem mostra, também, entre as várias expressões de alegria, uma certa ordem e disciplina. Ao observar as mulheres que se encontram sentadas, percebe-se que todas estão com as mãos e os pés na mesma posição. Além disso, as roupas demonstram uma certa semelhança no vestir e nos próprios penteados (deve-se ter em conta que, além de ser Preto-e-branco - PB, as cores da imagem também esmaeceram com o tempo, o que dificulta em alguns aspectos a análise), chegando a parecer que algumas delas usavam uniformes, uma espécie de tapa-pó. Além disso, a maior parte delas se coloca em uma pose recatada, discreta, o que se encontra muito vinculado ao perfil moralizante das escolas. Um ponto bastante interessante é que se pode perceber a presença de, ao menos, uma mulher negra entre elas (como já foi dito, o prejuízo das cores causa certas dificuldades). Outra característica da imagem é o fato de ser posada, porém, neste caso especificamente, isso não implica uma abordagem voltada especialmente para isso, pois, praticamente todas as fotografias de grupos de professores (e isso inclui as atuais) são posadas.

\section{Considerações finais:}

As fotografias apresentam as formas de pensamento de uma época, a sua autorepresentação. Fica marcado sobre o papel aquilo que a sociedade deseja mostrar de si mesma. Mas não se pode culpar somente a imagem, visto que o texto escrito tampouco se exime dessa culpabilidade. A imagem, calcada no texto e no contexto, abre espaço para as interpretações, permitindo ao pesquisador visualizar a auto-imagem de uma época, de um grupo, de um governo. Permanece, portanto, para a posteridade, aquilo que foi selecionado. Especialmente na década de 1920, quando os custos com as fotografias ainda eram bastante elevados e necessitava-se de profissionais para que o trabalho fosse executado, a seleção do que devia ficar era ainda mais crítica

As fotografias originais do arquivo do Grupo Escolar Dr. Joaquim Assumpção apresentam-se simétricas e centralizadas. Nas fotografias de inauguração de retratos, esses se encontram na posição central, evidenciando o tipo de cerimônia que se estava realizando. As fotografias de demonstrações de Educação Física em cerimônias cívicas e do Grupo de Escoteiros, aproveitaram-se da arquitetura das construções para dali iniciar a sua organização. O ponto central de todas as três é a pequena casa do zelador, construída junto ao muro, em frente a qual foi colocada a bandeira nacional, símbolo do patriotismo do momento. Colocando-a como referência central, traçaram-se várias fileiras de estudantes, tanto durante a apresentação, quanto no momento de formação. A fotografia da exposição de trabalhos manuais é a única que foi tirada de um ângulo oblíquo, que facilitou 
o enquadramento dos trabalhos realizados pelos alunos. A fotografia do corpo docente retoma a simetria das imagens anteriores.

Conforme tudo o que foi dito anteriormente, a compreensão do contexto da época permitiu o entendimento da importância da arquitetura escolar nesse período, da sua relação com a afirmação da república e de todo o seu ideário (organização do tempo expressa por meio do relógio, separação entre escola e cidade - evidenciada pela presença do muro, disciplina - percebida na formação dos alunos, patriotismo - verificada pela presença de bandeiras e símbolos nacionais), e, notadamente, com o movimento higienista, muito forte durante a Primeira República (afirmado pelas demonstrações de "educação physica", que é, ao mesmo tempo, uma forma de evidenciar o patriotismo).

As fotografias desse conjunto serviram para conhecer algumas práticas escolares da época e, também, como parâmetro para compreender os motivos que levaram à opção por determinadas imagens em detrimento de outras (quais fotografias eram importantes para a instituição escolar e quais eram importantes para o governo municipal). Todas as fotografias guardam em si uma intencionalidade, sejam elas oficiais ou institucionais. Além disso, um dos motivos que possibilitou o traçar de parâmetros entre os dois conjuntos fotográficos foi o fato de o Grupo Escolar Dr. Joaquim Assumpção ter sido considerado a principal escola fundada por Augusto Simões Lopes, deixando para trás o outro grupo escolar urbano, o Dona Antonia. Essas imagens permitem a compreensão do motivo pelo qual o referido grupo escolar encontrava-se no patamar mais elevado preconizado pelo "Regulamento da Instrucção", do governo Simões Lopes. Embora não sejam fotografias oficiais, tais imagens estão impregnadas do ideário governista republicano da época, especificamente, do governo Simões Lopes.

\section{Referências bibliográficas:}

ALMEIDA, Jane Soares de. Mulheres na Educação: missão, vocação e destino? In: SAVIANI, Demerval. O Legado Educacional do século XX no Brasil. Campinas, SP: Autores Associados, 2004, p. 59 a 108.

ALVES, Nilda. O Espaço Escolar e suas Marcas: o espaço como dimensão material do currículo. Rio de Janeiro: DP\&A, 1998.

BONATO, Nailda Marinho da Costa. A Educação Feminina no espaço escolar oficial do Rio de Janeiro do final do Império à Primeira República - a Escola Normal: uma escola para mulheres? In: Anais do I Congresso Brasileiro de História da Educação, Universidade Federal do Rio de Janeiro, 2000.

BORGES, Maria Eliza Linhares. História \& Fotografia. Belo Horizonte: Autêntica, 2003.

CORSETTI, Berenice. O poder em migalhas - a escola no Rio Grande do Sul na Primeira República. Tese de Doutorado. Santa Maria, Universidade Federal de Santa Maria, 1997.

JORNAL DIÁRIO Popular. 1927.

DUBOIS, Philippe. O ato fotográfico e outros ensaios. Campinas, SP: Papirus, 1993.

FABRIS, Annateresa (org.). Fotografia usos e funções no século XIX. São Paulo: Editora da Universidade de São Paulo, 1991.

FARIA FILHO, Luciano Mendes de. Dos Pardieiros aos Palácios: forma e cultura escolares em Belo Horizonte. São Paulo: USP, 1996. 
HILSDORF, Maria Lucia Spedo. História da Educação Brasileira: Leituras. São Paulo: Pioneira Thomson Learning, 2005.

LE GOFF, Jacques. História e Memória. Campinas, SP: Editora da UNICAMP, 1992.

LEITE, Mirian Moreira. Retratos de Família. São Paulo: Editora da Universidade de São Paulo, 1993.

JORNAL O LIBERTADOR, 1927.

PERES, Eliane Teresinha. Aprendendo formas de pensar, de sentir e de agir a Escola como oficina da vida: discursos pedagógicos e práticas escolares da Escola Pública Primária Gaúcha (1909-1959). Tese de doutorado. Universidade Federal de Minas Gerais, Belo Horizonte, 2000.

PERROT, Michelle. Os Excluídos da História: operários, mulheres e prisioneiros. Rio de Janeiro: Paz e Terra, 1988.

RELATÓRIO Intendencial de 1927.

SOUZA, Rosa Fátima. Templos de Civilização: Um Estudo sobre a Implantação dos Grupos Escolares no Estado de São Paulo. Tese de doutorado. São Paulo: USP, 1996.

A militarização da infância: Expressões do nacionalismo na cultura brasileira. In: Cadernos Cedes, ano XX, no 52, novembro/2000.

Fotografias escolares: a leitura de imagens na história da escola primária. In: Educar, Curitiba, n.18, p.75-101. 2001. Editora da UFPR.

Artigo recebido em: 18/3/2009

Aprovado para publicação em: 31/08/09

Revista HISTEDBR On-line, Campinas, n.34, p 19-36, jun.2009 - ISSN: 1676-2584 